EESTI NSV TEADUSTE AKADEEMIA TOIMETISED. 20. KÖIDE KEEMIA * GEOLOOGIA. 1971, NR. 4

ИЗВЕСТИЯ АКАДЕМИИ НАУК ЭСТОНСКОИ ССР. ТОМ 20 ХИМИЯ * ГЕОЛОГИЯ. 1971, № 4

удК 541.12

О. ЭИЗЕН, АННЕ ЭЛЬВЕЛЬТ, Л. КУДРЯВЦЕВА

\title{
ИССЛЕДОВАНИЕ ФИЗИКО-ХИМИЧЕСКИХ СВОЙСТВ НЕПРЕДЕЛЬНЫХ УГЛЕВОДОРОДОВ
}

\section{1. Плотность изомерных $H$-ноненов и $H$-деценов}

В настоящем сообщении приводятся результаты экспериментального определения плотности изомерных $\boldsymbol{H}$-ноненов и $н$-деценов при температурах $20-60^{\circ} \mathrm{C}$, а также полученные на их основе уравнения зависимости плотности от температуры.

В литературе результаты измерения плотности цис-и транс-изомеров ноненов и деценов нами не обнаружены. В работах $[1,2]$ приводятся только значения плотностей нонена-1 и децена-1, измеренные при различных температурах.

Транс-алкены, исследуемые в настоящей работе, были получены путем неполного гидрирования соответствующих алкинов с металлическим натрием в жидком аммиаке [3], цис-алкены - с помощью той же реакции при комнатной температуре в присутствии катализатора Линдляра.

Полученные вещества предварительно очищались ректификацией и окончательно - методом препаративной газовой хроматографии на при боре ПГК-3. Чистота веществ проверялась на хроматографе «Хром-2» на капиллярной колонке с наполнителем из полиэтиленгликоля 4000 при температуре $80^{\circ}$ и на хроматографе УХ-1 на метровой колонке с наполнителем из $\mathrm{AgNO}_{3} / 1,4$-бутиленгликоля на хромосорбе $B$ при той же температуре.

Плотность изомеров ноненов и деценов определялась в пикнометрах емкостью 2,5 мл, которые были предварительно прокалиброваны по воде при температурах исследования.

Температура термостата, в который помещались пикнометры, контролировалась выверенным ртутным термометром с точностью $\pm 0,05^{\circ}$. Величина плотности рассчитывалась по формуле [4]

$$
d_{4}^{t}=\frac{P_{a}^{t}}{P_{b}^{t}}\left(E_{4}^{t}-e\right)+e,
$$

где $P_{a}^{t}$ и $P_{b}^{t}$ - вес равных объемов алкена и воды соответственно при температуре $t, E_{4}^{t}$ - плотность воды при температуре $t, e=0,00120-$ плотность воздуха (колебания плотности лабораторного воздуха не учитывались). Результаты контрольных опытов по определению плотности бензола и циклогексана при $20^{\circ}$ с точностью до 0,0001 совпали с данными, приведенными в литературе $[1,2]$. Для нонана эти измерения были выпол- 


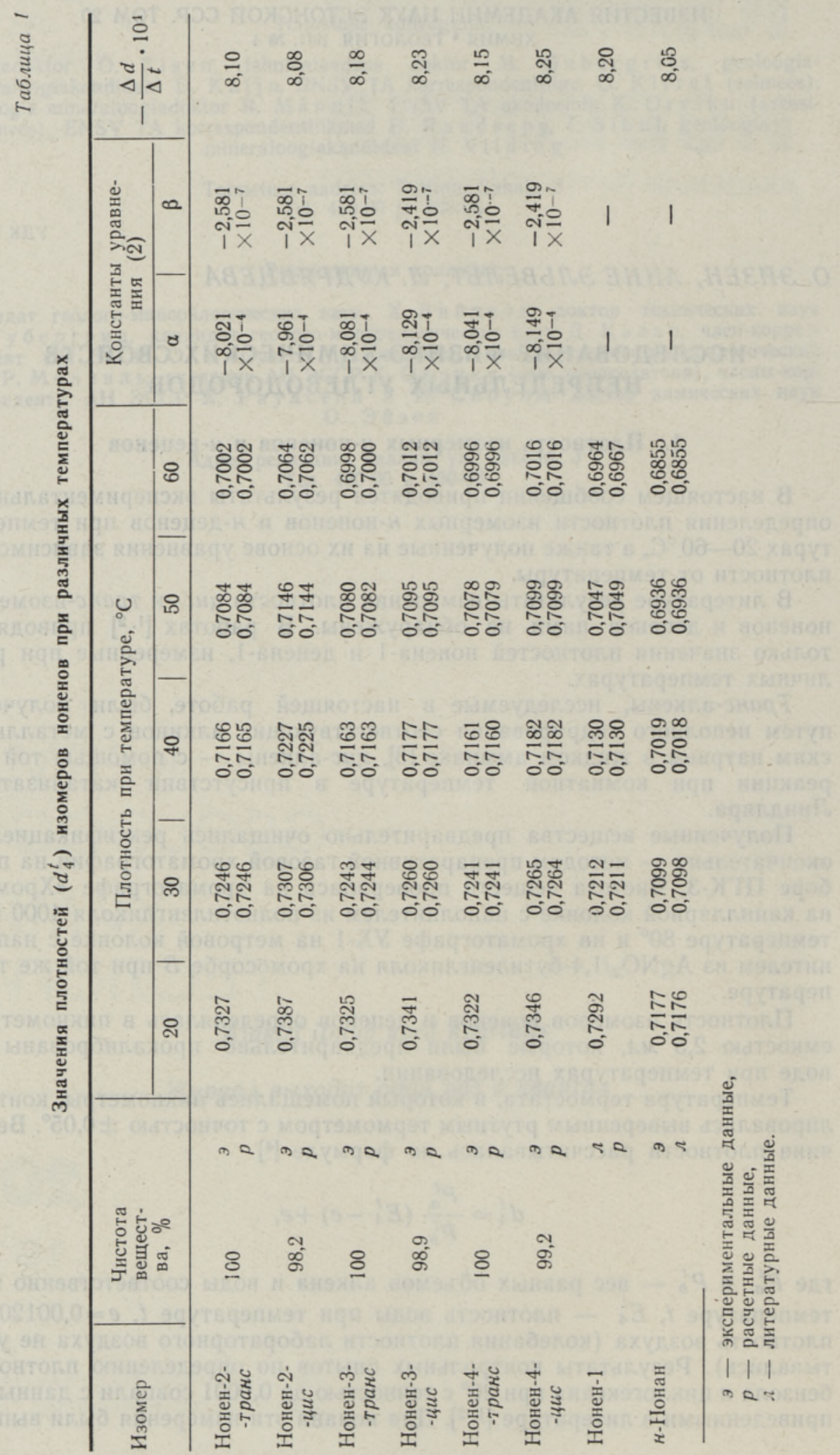




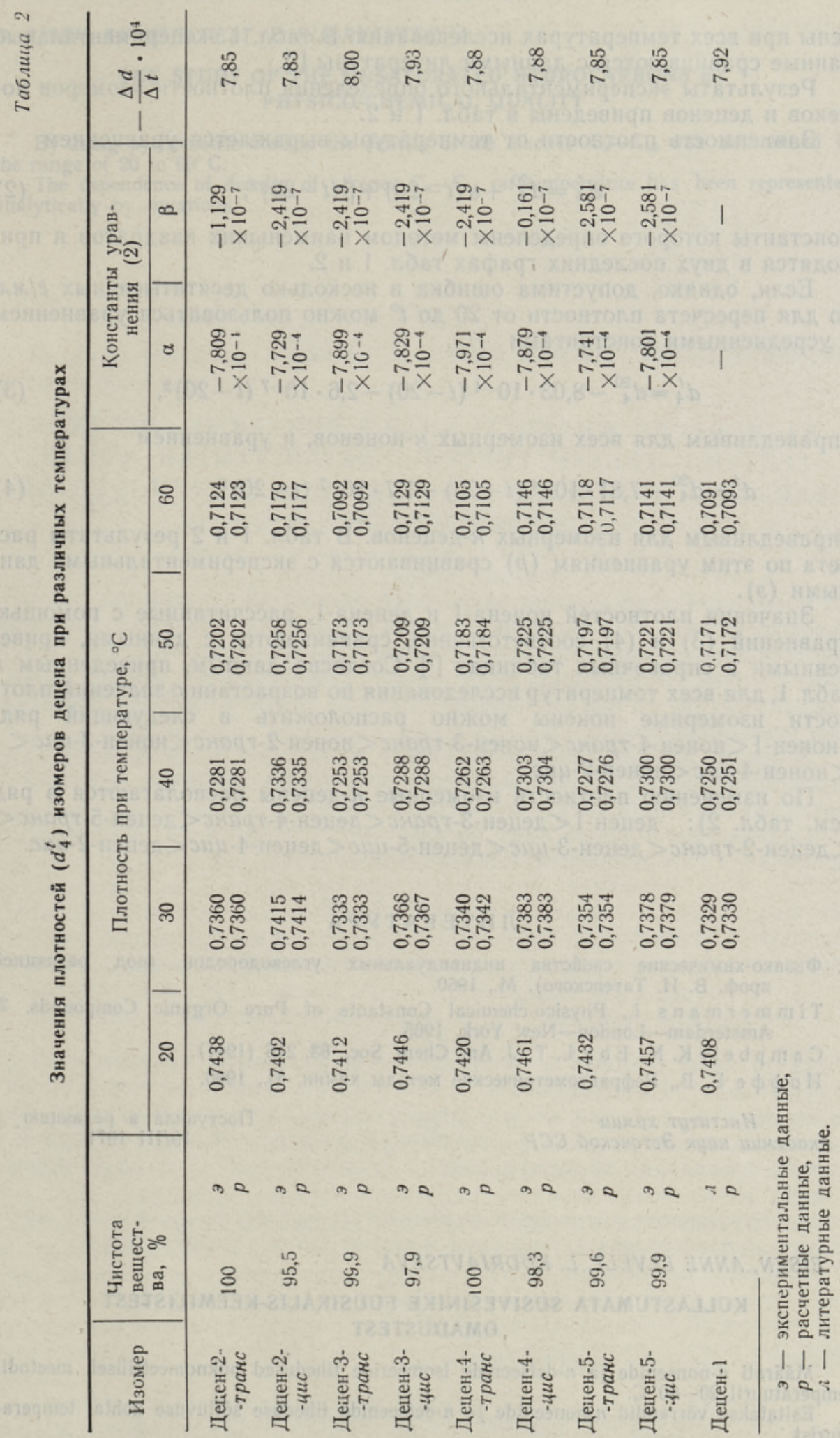


нены при всех температурах исследования. В табл. 1 экспериментальные данные сравниваются с данными литературы ['].

Результаты экспериментального определения плотности изомеров ноненов и деценов приведены в табл. 1 и 2.

Зависимость плотности от температуры выражается уравнением

$$
d_{4}^{t}=d_{4}^{20}+\alpha(t-20)+\beta(t-20)^{2}
$$

константы которого определены методом наименьших квадратов и приводятся в двух последних графах табл. 1 и 2.

Если, однако, допустима ошибка в несколько десятитысячных г/мл, то для пересчета плотности от 20 до $t^{\circ}$ можно пользоваться уравнением с усредненными константами

$$
d_{4}^{t}=d_{4}^{20}-8,03 \cdot 10^{-4}(t-20)-2,6 \cdot 10^{-7}(t-20)^{2},
$$

справедливым для всех изомерных 4 -ноненов, и уравнением

$$
d_{4}^{t}=d_{4}^{20}-7,81 \cdot 10^{-4}(t-20)-1,7 \cdot 10^{-7}(t-20)^{2}
$$

справедливым для изомерных н-деценов. В табл. 1 и 2 результаты расчета по этим уравнениям ( $p)$ сравниваются с экспериментальными данными (э).

Значения плотностей нонена-1 и децена-1, рассчитанные с помощью уравнений (3) и (4) соответственно, сравниваются с данными, приведенными в справочных таблицах [']. Согласно данным, приведенным в табл. 1, для всех температур исследования по возрастанию значений плотности изомерные нонены можно расположить в следующий ряд: нонен-1 <нонен-4-транс $<$ нонен-3-транс $<$ нонен-2-транс $<$ нонен-3-цис $<$ $<$ нонен-4-цицс <нонен-2-цис.

По изменению плотности изомерные $н$-децены располагаются в ряд (см. табл. 2): децен-1<децен-3-транс <децен-4-транс $<$ децен-5-транс $<$ $<$ децен-2-транс <децен-3-циис <децен-5-ццис <децен-4-циис <децен-2-ццис.

\section{Л ИТЕРА Т У Р А}

1. Физико-химические свойства индивидуальных углеводородов (под редакцией проф. В. И. Татевского). М., 1960.

2. Timmermans I., Physico-chemical Constants of Pure Organic Compounds, 2, Amsterdam-London-New York, 1965.

3. C a m p bell K. N., E b y L. T., J. Am. Chem. Soc., 63, 216 (1941).

4. Иоффе Б. В., Рефрактометрические методы химии, М., 1960.
Институт химии
Академии наук Эстонской ССР
Поступила в редакцию 19/III 1971

\section{O. EISEN, ANNE ELVELT, L. KUDRJAVTSEVA}

\section{KULLASTUMATA SUSIVESINIKE FUUSIKALIS-KEEMILISTEST OMADUSTEST}

Määrati $n$-noneenide ja $n$-detseenide isomeeride tihedused püknomeetrilisel meetodil temperatuuril $20-60^{\circ} \mathrm{C}$.

Esitatakse võrrandid $n$-noneenide ja $n$-detseenide tiheduse sōltuvuse kohta temperatuurist. 


\section{O. EISEN, ANNE ELVELT, L. KUDRYAVTSEVA}

\section{THE STUDY OF THE UNSATURATED HYDROCARBONS BY PHYSICO-CHEMICAL QUALITY}

By using pycnometric method the density of the alkenes $\mathrm{C}_{9}-\mathrm{C}_{10}$ was determined in the range of 20 to $60^{\circ} \mathrm{C}$.

The dependence of density of alkenes $C_{9}-C_{10}$ on temperature has been represented analytically by equations. 